\title{
Los Directorios de Catequesis de 1971 y 1997
}

Giuseppe Biancardir

\section{Resumen:}

Este artículo presenta un desarrollo histórico de la formación tanto del Directorio Catequístico General (1971) como del Directorio General para la Catequesis (1997). Se desarrolla tanto la situación que les dio origen como el proceso de redacción al que fueron sometidos. Posteriormente se detallan sus contenidos a grandes rasgos, así como unos apuntes de valoración, que permiten situarlos en su contexto, así como las novedades que aportaron en su momento. Una vez presentados se realiza una comparación entre ellos señalando tanto los elementos de continuidad como las novedades, así como una valoración de lo que supuso el Catecismo de la Iglesia Católica (1997) y su impacto en el Directorio General para la Catequesis de 1997.

\section{Palabras clave:}

Directorio General para la Catequesis, Directorio Catequístico General, Catecismo Iglesia Católica, Concilio Vaticano II

1 Salesiano. Profesor emérito de Historia de la catequesis, Universidad Pontificia Salesiana de Roma. 


\section{El Directorio Catequístico General (DCG 1971)²}

\subsection{Orígenes y redacción ${ }^{3}$}

En los orígenes del DCG debe situarse la disposición conciliar de Christus Dominus n. 44c, que prevé: "un directorio para la enseñanza catequística del pueblo, en el cual se trate de los principios fundamentales de la misma enseñanza y de su orientación, así como de la elaboración de los libros, relativos a esta materia”.

Y eso porque - como ya se ha recordado - la Iglesia reunida en su asamblea máxima, de nuevo una vez más renuncia a un catecismo universal en favor de un texto que, aunque muy cualificado, quiere ofrecer únicamente indicaciones, estímulos y orientaciones generales para promover y guiar la labor catequística de las Iglesias locales.

El trabajo preparatorio del nuevo texto toma inicio casi inmediatamente, pero a hurtadillas. En efecto, acabado el Concilio, la Congregación del Concilio, posteriormente - desde agosto de 1967 - llamada

2 Dada la notoriedad y la amplia difusión, incluso en soporte informático, de los documentos del magisterio, además de la edición oficial citaremos únicamente aquellas que van acompañadas por un comentario o las reproducidas en colecciones de textos con manifestaciones sobre ellos. En el caso del DCG: AAS 64 (1972) 97-176; G. Concetti (ed.), Evangelizzazione e catechesi, Massimo, Milano 1980, 15-89; G.M. Medica (ed.), Documenti su catechesi ed evangelizzazione, Elledici, Torino 1988, 115-190; EV4, 224-399. Edición sinóptica con otros documentos catequísticos oficiales: La catechesi negli anni 80. Da "Il rinnovamento della catechesi" alla "Catechesi tradendae". Sinossi dei documenti ecclesiali sulla catechesi: 1970-1979, Paoline - Centro Catechistico Paolino, Roma 1981, 137207. Ediciones con comentarios sistemáticos: S. Congrégation pour le Clergé, Directoire Catéchétique Général. Traduction française et commentaires, publicado como Supplément a Cse 11 (1971) 45; B.L. Marthaler; Consejo Episcopal Latinoamericano - Celam, Evangelización y Catequesis. Diez Documentos del Magisterio Eclesiástico con indice analítico, Departamento de Catequesis 2 - DECAT, Bogotá 1986, 111-226.

3 Reconstruyen el contexto y las vicisitudes que se encuentran en el origen inmediato del DCG: Palazzini, L'opera svolta dalla S. Congregazione per il Clero in campo catechistico, en Sacra Congregazione per il Clero, Atti del II Congresso Catechistico Internazionale. Roma, 20-25 septiembre 1971, Studium, Roma 1972, 147-212; aquí 208-212; B.L. Marthaler, The Genesis and Genius of the General Catechetical Directory, en B.L. Marthaler (ed.), Catechetics in Context, XVI-XXX. 
"para el Clero" 4 , competente en la materia, pregunta a la Secretaría de Estado, a quién compete la redacción del directorio y a ella le viene asignada dicha tarea, entre junio y noviembre de 1966. El dicasterio romano se preocupa entonces de solicitar la colaboración de universidades eclesiásticas e institutos competentes, enviando, no obstante, ya un primer borrador de ocho capítulos y solicitando un juicio antes de finales de enero de 1967. Posteriormente, le siguen otros trabajos de redacción sobre el nuevo documento, mientras que en agosto de ese mismo año el cardenal J. Villot, prefecto de la que en adelante ya es la Congregación para el Clero, recibe de Pablo VI el mandato de informar sobre el tema al primer Sínodo de los obispos previsto para el otoño siguientes.

En este momento, para mejor comprender el resultado final del trabajo de redacción del DCG, es conveniente recordar brevemente el acontecimiento sinodal de 1967 y el clima eclesial concomitante, es decir aquel clima extremadamente vivaz y encendido, marcado por contestaciones y fuertes contraposiciones entre tradicionalista e innovadores. Así pues, será suficiente recordar, de aquel periodo, el emblemático fenómeno de las comunidades de base que, partiendo de acusaciones de tipo socio-económico y político expresadas en los enfrentamientos de la Iglesia (para quienes la Iglesia es una institución "de los ricos", vinculada con el poder capitalista), pasan a una controversia mucho más profunda, de tipo teológico, menoscabando el ordenamiento sacramental, moral, jerárquico y disciplinar. De igual modo, y prescindiendo de las comunidades de base

4 El cambio del nombre se produjo a raíz de la Constitución apostólica de Pablo VI Regimini Ecclesiae universae para la reorganización de la Curia romana (15.8.1967). Aún con el nombre cambiado, la Congregación, a través de su Oficina Segunda, asume las tareas de lo que anteriormente era la Oficina Catequística Central instituida por Pio XI con el motu proprio Orbem catholicum, conservando la responsabilidad de animación, coordinación y control de la catequesis a nivel de Iglesia universal. Cf. AAS 59 (1967) 885-928; y 908-912. Y esto hasta finales del 2013, cuando Benedicto XVI, con el motu proprio Fides per doctrinam (16.1.2013), trasfirió la competencia catequística al Pontificio Consejo para la promoción de la Nueva Evangelización. El texto del documento se halla en AAS 105 (2013) 136139; OR del 26.1.2013, 4; RD 58 (2013) 133-135, AC 53 (2013) 237, 21-24.

5 Se sintetizan aquí a continuación las minuciosas informaciones de Palazzini, L'opera svolta dalla S. Congregazione per il Clero in campo catechistico, 208-212; en particular, sobre la indicación suministrada a Villot, Cf. 209. 
cabría recordar también una vez más los cristianos por el socialismo, contestatarios de la unidad de los católicos en campo político; unidad tradicional y generalmente sostenida por la jerarquía. Podríamos añadir: las innovadoras $\mathrm{y}$, a veces discutibles, elaboraciones de reputados teólogos de la época; el evidente crecimiento de la crisis en el campo vocacional; las críticas, formuladas incluso de diversos ambientes católicos, a las posiciones oficiales asumidas por la Iglesia en temas de disciplina eclesiástica (celibato), regulación de la natalidad (Humanae vitae, 1968), divorcio, aborto y temas similares, y se comprenderá fácilmente cómo muchos, entre ellos varios pastores especialmente aquellos de orientación más tradicionalista, en aquel primer periodo postconciliar que presenció la redacción del DCG, se vieron inducidos a subrayar con preocupación la desorientación, la confusión y los auténticos quebrantos en el campo doctrinal y moral, vividos por muchos fieles ${ }^{6}$.

Así pues, no nos sorprende que el 24 de julio del 1966, el cardenal Ottaviani, prefecto de la Congregación para la Doctrina de la Fe, invitase a las Conferencias Episcopales, mediante una carta reservada, a un serio análisis de los posibles errores que se insinuaban en sus Iglesias. Los prelados, de modo particular, son llamados a tomar en consideración los riesgos de derivaciones doctrinales en torno a diez puntos precisos: Revelación y Tradición, naturaleza de las fórmulas dogmáticas, verdad y relativismo, magisterio ordinario, cristología, sacramentos en general, sacramento de la penitencia, pecado original, doctrina moral y ecumenismo ${ }^{7}$.

6 Sobre aquel particular momento eclesial, marcado por macroscópicos y difusos movimientos contestatarios eclesiales, Cf. el cuadro global ofrecido por R. Aubert, La situation de l'Église au lendemain des "golden sixties", en L'Esortazione apostolica di Paolo VI "Evangelii Nuntiandi". Storia, contenuti, ricezione. Colloquio internazionale di studio. Brescia, 22-23-24 setiembre 1995, Pubblicazioni dell'Istituto Paolo VI, Brescia 1998, 23-52, y en: Paolo VI e la crisi postconciliare. Paul VI. und die Nachkonziliare Krise. Giornate di studio / Studientage. Bressanone / Brixen, 25-26 Febbraio / Februar 2012, a cargo de J. Ernesti, Brescia, Pubblicazioni dell'Istituto Paolo VI 2013.

7 La carta y las respuestas suscitadas, destinadas per se a permanecer secretas, fueron, no obstante, divulgadas por algunas conferencias episcopales. Así pues, la Epistula del cardenal Ottaviani fue publicada en AAS 58 (1966) 659-661; una versión en italiano fue reproducida por G. Caprile, Il Sinodo dei vescovi. Prima assemblea generale (29 settembre - 29 ottobre 1967), Edizioni "La Civiltà Cattolica” Roma 1968, 623-624; una síntesis de la misma, bajo el título Dieci questio- 
Las turbulencias de esta época, en los años que van desde 1966 al 1968, se agravan debido al clamor internacional y a las discusiones suscitada por el célebre De Nieuwe Katechismus, o Nuevo catecismo holandés. El texto suscita muchas preocupaciones en cuanto a la integridad y ortodoxia de los contenidos. Para responder a ello, la comisión cardenalicia encargada de estudiar la cuestión del discurso del catecismo, en junio de 1967, casi por unanimidad, sugiere al pontífice también la elaboración de un catecismo universal, considerado como remedio a la posible difusión de formulaciones imprecisas e incompletas en cuanto al aspecto doctrinal. Pablo VI, no obstante, respetuoso con las indicaciones conciliares - como ya hemos visto confía al cardenal Villot, llamado a presidir la inminente asamblea, el mandato de informar a los padres sinodales sobre los trabajos concernientes al nuevo directorios.

ni sottoposte ai vescovi dalla Congregazione per la dottrina, se encuentra en Il Regno-Attualità 11 (1966) 486. De las respuestas de los episcopados, se conocen las de los obispos holandeses y franceses: La risposta dell'episcopato olandese all'inchiesta del card. Ottaviani (testo originale con le varianti definitive) [...], Il Regno-Documenti 13 (1968) 101-108 (documento ofrecido también en A. Chiaruittini (ed.), Dossier del Catechismo olandese, Mondadori, Milán 1968, 70-97); "Réponse de la Conférence épiscopale française à la lettre circulaire de la Congrégation pour la Doctrine de la foi”, La Documentation Catholique 49 (1967) 327-338. La respuesta francesa fue difundida también por el diario católico "La Croix"; acto que suscita la explícita reprobación de Pablo VI: A. Wenger, "Paul VI et La Croix", en Paul VI et la modernité dans l'Église. Actas del coloquio organizado por la Escuela Francesa de Roma (Roma 2-4 de junio 1983), École française de Rome, Roma 1984, 747-764; y 757-759.

8 A decir verdad, en vísperas del Sínodo parece reinar, quizás, una cierta confusión en las informaciones sobre las intenciones de las autoridades romanas sobre el futuro documento catequístico universal, así como también sobre el real mandato asignado a Villot. Probablemente es un síntoma de esta confusión lo que escribe M. Simon, Un catéchisme universel, 287-292, 295, proponiendo la hipótesis de que Pablo VI hubiese encargado a Villot de poner al corriente a los padres sinodales no sobre el directorio, solicitado por el Vaticano II, sino sobre un futuro catecismo universal. Pero, con toda corrección, el estudioso belga utiliza el condicional (sobre todo 295 y nota 737). En efecto, su hipótesis va evidentemente contra las prestigiosas indicaciones de Palazzini - reproducida por nosotros - que, en calidad de secretario de la Congregación para el Clero, pudo acceder directamente a fuentes de primera mano. Más aún, choca claramente contra la posición contraria ante la idea de un formulario universal mantenida durante todos los trabajos sinodales por las autoridades romanas, y expresada explícitamente mediante dos de sus intervenciones oficiales a los que enseguida haremos referencia. 
De todas formas, fue en este contexto de preocupación doctrinal y de probable comunicación defectuosa de noticias e intenciones como, en otoño de 1967, tuvo lugar el primer sínodo de los obispos (29 de septiembre - 29 de octubre) ${ }^{9}$. Su orden del día, aunque muy heterogéneo, en su primitiva versión plantea como primer punto el análisis de los peligros que amenazan la fe y sus posibles remedios ${ }^{10}$, al cual le siguen los demás temas previstos: revisión del Código de derecho canónico, seminarios, matrimonios mixtos, reforma litúrgica ${ }^{11}$.

En la práctica, el análisis de las opiniones peligrosas para la fe y del ateísmo pasa a segundo plano, desarrollándose sobre todo en las asambleas plenarias que tuvieron lugar entre el 4 y el 10 de octubre, a partir de un informe introductorio del cardenal M. Browne ${ }^{12}$. En definitiva, dicho informe retoma y amplía los puntos problemáticos ya formulados en la citada carta del cardenal Ottaviani y expuestos en un documento ad hoc enviado precedentemente a los padres ${ }^{13}$. Son más de 80 los prelados que intervienen oralmente sobre el tema, mientras otra veintena entregan por escrito sus observaciones. Y no pocos de ellos, cuando se abordan los posibles remedios a la situación negativa en lo referente a la fe y a la moral que se constatan en esa época, entre otros a nivel teológico, sugieren la creación de una comisión teológica internacional llamada a reflexionar sobre las problemáticas doctrinales ${ }^{14}$, mientras que sobre un plano más pa-

9 Sobre el primer Sínodo, abundan las noticias y la documentación Caprile, Il Sinodo dei vescovi. Prima assemblea generale y Concetti, Bilancio e documenti del Sinodo dei vescovi. Documenti ufficiali, commenti, dichiarazioni, echi della stampa sulla prima assemblea generale (29 settembre-29 ottobre 1967), Massimo, Milán 1968.

10 Cf. Caprile, Il Sinodo dei vescovi. Prima assemblea generale, 38; Cf. R. Laurentin, L'enjeu du Synode, 128-146.

11 Sobre estos temas posteriores ver también R. Laurentin, L'enjeu du Synode, 147-181.

12 El texto de la exposición está en Enchyridion Symbolorum (ES) 1, nn. 329-353 y fue sintetizado por Caprile, Il Sinodo dei vescovi. Prima assemblea generale, 155-158 y Concetti, Bilancio e documenti del Sinodo dei vescovi, 131-135.

13 El documento está presentado íntegramente en ES 1, nn. 251-291. Una síntesis en Caprile, Il Sinodo dei vescovi. Prima assemblea generale, 146-155.

14 Es sabido que la solicitud fue acogida por Pablo VI quien, el 11.4.1969, instituyó una Comisión Teológica Internacional ante la Congregación para la Doctrina de la Fe, la cual aprobó el estatuto ad experimentum. La aprobación definitiva llegaría con el motu proprio Tredici anni iam de Juan Pablo II, el 6.8.1982. 
storal solicitan precisamente un texto catequístico universal ${ }^{15}$. Tal es el caso, por ejemplo, del cardenal F. Quiroga y Palacio (España) y de los obispos J. Wright (Estados Unidos), M. González Martin (Barcelona), A. Ddungu (Uganda), E. Mason (Sudán), M. Doumith (Líbano) y P. Guerra Campos (Madrid) ${ }^{16}$. La especificación de lo sugerido es variada: va desde la redacción de una Regula fidei formulada con un lenguaje adaptado al hombre actual hasta un verdadero y propio catecismo universal, conformado por una actualización del catecismo tridentino o de un catecismo del Vaticano II redactado ex novo con la ayuda de expertos ${ }^{17}$.

Con todo, el informe final, que intenta una síntesis del debate, confiada al cardenal F. Seper, no hace mención ninguna a las sugerencias expresadas en cuanto a un posible recurso universal de índole catequística $^{18}$; un silencio que en consecuencia suscita de nuevo la petición de explicaciones en algún prelado ${ }^{19}$.

Ya al final de las tareas sinodales, dos intervenciones de las autoridades vaticanas ponen oficial y definitivamente fin a la posibilidad de llegar a la redacción de un formulario catequístico universal. El 25 de octubre es el turno de una breve nota leída en la asamblea por el cardenal Seper, que se refiere explícitamente al dictamen conciliar (CD 44c) $)^{20}$. La disposición conciliar es confirmada por el cardenal Villot. Éste, el 27 de octubre de 1967, en conformidad con el mandato recibido de Pablo VI, mediante una apropiada y clara comunicación recuerda la naturaleza y finalidad de un directorio ca-

15 El debate se encuentra resumido por Caprile, Il Sinodo dei vescovi. Prima assemblea generale, 141-236 e Concetti, Bilancio e documenti del Sinodo dei vescovi, 344-354.

16 En Caprile, Il Sinodo dei vescovi. Prima assemblea generale, ver respectivamente las 172, 180-181, 190, 196-197, 201-202, 210-211.

17 Una síntesis de las propuestas está Caprile, Il Sinodo dei vescovi. Prima assemblea generale, 221. Para indicaciones más particularizadas ver el índice analítico de 665, o la minuciosa catalogación de las indicaciones preparada por M. Simon, Un catéchisme universel, 295-298.

18 Cf. Caprile, Il Sinodo dei vescovi. Prima assemblea generale, 227-232.

19 Caprile, Il Sinodo dei vescovi. Prima assemblea generale, 233 e 235. La atención del Sínodo se halla también en el origen de un documento redactado por una comisión particular, reproducido en Enchiridion Vaticanum (EV) 2, nn. 1714-1725 y en Il primo Sinodo dei vescovi, 121-129.

20 Se lo puede leer en Caprile, Il Sinodo dei vescovi. Prima assemblea generale, 226. 
tequístico, invitando a los obispos a colaborar en su redacción ${ }^{21}$. No obstante, cabe señalar al respecto, que el cardenal prefecto parece no querer desatender del todo la solicitud expresada por aquellos obispos que habían sugerido una especie de catecismo universal: en su intervención, en efecto, confía al futuro directorio también la función de exponer orgánicamente, aunque sea en términos necesariamente sintéticos, el mensaje de la salvación ${ }^{22}$.

Para dar seguimiento efectivo a todo lo declarado oficialmente en el Sínodo, ya a finales del mismo 1967, se inicia una consulta preliminar a las conferencias episcopales y a la curia romana. En la primavera de 1968 se establece una comisión de expertos con la tarea de redactar el borrador del documento ${ }^{23}$, prestando la debida atención a las indicaciones obtenidas por la consulta efectuada. De dicha comisión forman parte dos italianos, Mons. A. Del Monte, director del Ufficio Catechistico Nazionale, y Mons. S. Goretti, del Ufficio Secondo (Ufficio Catechistico Centrale) anexo a la Congregación para el Clero, ambos ya desde hacía tiempo dedicados a la elaboración del Documento base para la catequesis italiana del postconcilio; lo cual explica las notables afinidades entre los dos textos. ${ }^{24}$.

El trabajo de los expertos es sometido a una posterior consulta en la cual adquieren particular relieve los pareceres de las Congregaciones romanas y de una oportuna comisión de teólogos. Sobre la base de estas nuevas aportaciones va madurando la redacción definitiva del texto que es promulgado oficialmente el 11 de abril de 1971, solemnidad de la Pascua ${ }^{25}$.

21 Caprile, Il Sinodo dei vescovi. Prima assemblea generale, 562-563. Cf. también Il primo Sinodo dei vescovi, 131-133 y Concetti, Bilancio e documenti del Sinodo dei vescovi, 158-160.

22 Simon, Un catéchisme universel, 301-303. Anticipamos ya que, en efecto, los redactores del DCG obedecerán a esta última orientación.

23 Simon, Un catéchisme universel, 303-306.

24 Cf. sobre estos informes, G.M. Medica, Il Documento di base della CEI e il Direttorio Catechistico Generale, en G.M. Medica (ed.), Dal Documento di Base ai nuovi catechismi alla catechesi viva. Storia, dimensioni, piste di riflessione e di ricerca, Torino-Leumann, Elledici 1974, 37-69.

25 Simon, Un catéchisme universel,307-313. Indicaciones más detalladas, a nivel de archivo, en Palazzini, L'opera svolta dalla S. Congregazione per il Clero in campo catechistico, 210-212. 


\subsection{Contenidos}

El documento, según la orientación conciliar, no va directamente dirigido a los catequistas, sino más bien a los obispos y a cuantos, colaborando con ellos, están dedicados a organizar y animar la catequesis en las iglesias locales.

El DCG, tras el proemio, se presenta subdividido en seis partes que se difunden en 234 párrafos.

- Las reflexiones iniciales de la primera parte tratan de poner de relieve la actualidad del problema catequístico a partir de la situación del mundo y de la Iglesia al inicio de los años setenta (nn. 1-9)

- La segunda parte describe la naturaleza, modalidades y funciones de la catequesis en el contexto del más amplio ministerio de la Palabra (10-35).

- En su tercera parte el texto se dedica a puntualizar los criterios según los cuales se deben proponer las verdades cristianas, reiterando, al mismo tiempo, también las más importantes entre ellas (36-69).

- La cuarta parte está asignada a la presentación de los elementos fundamentales de toda pedagogía catequística (70-76), en tanto que en la quinta encontramos un análisis específico de la catequesis con referencia a las diversas edades de los aludidos (77-97).

- La sexta parte coloca el servicio catequístico en la articulación pastoral del ministerio de la Palabra desarrollado en las comunidades cristianas. Las Iglesias locales, ante todo, están invitadas a analizar, según el correcto proyecto pastoral, la situación en que se encuentran insertas y a valorar el servicio prestado. Tras el análisis, les corresponderá la tarea de la programación. La misma deberá ocuparse, dentro del campo específico catequístico, de la elaboración de los directorios locales, de la investigación catequística, de la formación de los catequistas, de la elaboración de los programas, catecismos y textos, además de la utilización de los medios audiovisuales; todo ello dentro de un marco de organización y colaboración a nivel local pero también de la Iglesia universal (98-134).

El documento se concluye con un Addendum que establece orientaciones precisas con relación al problema de la iniciación a los sacramentos de la Penitencia y de la Eucaristía. Este añadido, que puede ser considerado como algo distinto del propio y verdadero Directorio, pretende precisar la propuesta oficial de la Santa 
Sede con respecto al problema de la relación entre Penitencia y Eucaristía en el proceso de iniciación de los niños. De hecho, en aquella época, en diversas realidades locales y sobre la base de razones de tipo eminentemente psicológico, se había llevado a cabo la opción de iniciar a los niños en la celebración de la Penitencia después de haber recibido ya, incluso varias veces, la Eucaristía. Así sucedía, por ejemplo, en la República Federal Alemana; en aquellos años, en un Rahmenplan, o "plan de conjunto" para la enseñanza religiosa lanzado en 1967, los obispos alemanes habían indagado la posibilidad, rápidamente traducida por muchos en práctica, de posponer la confesión con respecto a la primera comunión ${ }^{26}$.

Frente a estas opciones, en un primer momento, se piensa en aludir al problema en DCG 106, donde se hace referencia a la normativa relativa a la catequesis sacramental. Luego, la elección cae sobre la fórmula del Addendum, sobre el cual la intervención de los obispos estaba aún por precisar con exactitud, debido a la perdurable inaccesibilidad de la documentación de los archivos ${ }^{27}$. En cualquier caso, el texto, preparado sobre todo por teólogos, confirma la validez de la praxis tradicional según la cual la primera comunión debe ir precedida por la confesión, sin por ello excluir posibles derogaciones, pero previo el beneplácito de la

26 Cf. A. Exeler, "L'évolution de la catéchèse et de la pédagogie religieuse en Allemagne Fédérale, 1965-1975”, Lumen Vitae 30 (1975) 327-344; y 330, y cuanto se dirá en el caso sobre Alemania a propósito del citado Rahmenplan.

27 Según una información oficial dirigida a los participantes del segundo congreso catequístico internacional, brevemente expuesto, en junio de 1970, este texto habría estado sometido a una consulta regular, obteniendo "la aprobación de la clara mayoría de los episcopados" (Sacra Congregazione per il Clero, Atti del II Congresso Catechistico Internazionale, 461, nota 1). Más sintéticas las expresiones de Palazzini, L'opera svolta dalla S. Congregazione per il Clero in campo catechistico, recogidas en la 211 del dicho volumen, que incluso podrían aludir a una simple información sobre el documento dada por el Vaticano a las Conferencias episcopales. De simple "información" habla explícitamente el meticuloso M. Simon, Un catéchisme universel, 314, nota 768, disminuyendo además el alcance de la aprobación expresada con respecto al Addendum por parte de la "neta mayoría de los episcopados", si es cierto que solamente 27 conferencias episcopales respondieron a la consulta concerniente al borrador de todo el DCG. 
Santa Sede y oídas las conferencias episcopales. En consecuencia, las mismas conferencias son invitadas a revisar, a la luz de esta precisa orientación, las diversas prácticas eventualmente instauradas en sus territorios y a ponerse de acuerdo con la Santa Sede ${ }^{28}$.

\subsection{Apuntes de valoración}

Queriendo proceder a una breve valoración de este primer documento catequístico postconciliar para toda la Iglesia, es preciso reconocer globalmente que el mismo "representa un momento importante en la realización de las instancias pastorales de renovación" ratificadas por el Vaticano II, y que "salen al encuentro de las más vivas exigencias de la catequesis contemporánea, constituyendo un intento valiente y equilibrado de afrontar abiertamente los problemas acuciantes que la cultura plantea hoy a la fe" ${ }^{29}$.

Nos encontramos ante un texto de indole pastoral. Conscientes de esta peculiaridad, los redactores del documento, tomando como

28 Sobre este tema, a continuación, se registrarán aún diversas fricciones entre autoridades romanas y episcopados de América del Norte y de Europa Occidental. Pero ya el 24.5.1973, una Declaratio conjunta de las Congregaciones para la Disciplina de los Sacramentos y para el Clero establecerá el fin de toda experimentación al respecto, confirmando la disciplina tradicional; Cf. AAS 65 (1973) 410, o bien EV 4, 398-399, o Il Regno-Documenti 18 (1973) 395. Como el problema sigue en pie, se producirán otras intervenciones de Roma orientados a confirmar la norma vaticana, es decir una carta del prefecto de la Congregación para el Culto Divino y la Disciplina de los Sacramentos dirigida con fecha de 31.3.1977 a los presidentes de las Conferencias Episcopales (sobre lo cual Cf. EV 6, nn.166-174), seguida del Responsum a una duda sobre el tema dado por las dos citadas congregaciones el 20.5.1977, disponible en AAS 69 (1977) 427; EV 6, n. 175, OR del 28.5.1977, 1. A justificar el dispositivo de la curia romana se dedica, entre otros, el entonces obispo de Munich, cardenal Ratzinger, mediante carta pastoral reproducida en $O R$ del 7-8.11.1977, 2, y en J. Ratzinger, Prima confessione e prima comunione dei fanciulli, Torino-Leumann, Elledici 1978; en apéndice el pequeño fascículo ofrece el citado Responsum (17) y las directivas del episcopado alemán para dar cumplimiento a las indicaciones de la curia (12-16). La norma tradicional encontrará posteriormente su codificación definitiva en el canon 914 del nuevo Código de 1983.

29 G. Groppo, "Direttorio Catechistico Generale", en J. Gevaert (ed.), Dizionario di Catechetica, Elledici, Torino-Leumann 1986, 221-222; y 222. 
modelo la renombrada Nota previa colocada al frente de la Gaudium et spes, reconocen desde el Proemio del DCG que no todas las partes del directorio tienen la misma importancia. Las partes que tratan de la divina revelación, de la naturaleza de la catequesis, de los criterios del anuncio cristiano y de sus más importantes contenidos, tienen valor para todos. En cambio, las partes que tratan de la situación actual, la metodología, el tipo de catequesis para las diversas edades, como necesariamente se derivan en gran parte de ciencias humanas, teóricas y prácticas, sujetas a una evolución, son tratadas más bien como indicaciones y sugerencias ${ }^{30}$.

Particularmente logradas resultan los puntos que desarrollan los siguientes temas ${ }^{31}$ :

- Naturaleza y funciones de la catequesis (16-35). Ésta, de por sí, según una subdivisión tradicional del ministerio profético se halla encuadrada entre el kerigma, o evangelización misionera, y la homilía y la teología (17). Pero el DCG, demuestra haber recibido la aportación del movimiento catequístico cuando no limita las finalidades del ministerio catequístico a la instrucción en la fe, sino que las especifica en términos mucho más amplios, tales como: la atención a la madurez de la fe de los individuos y de las comunidades (21); la iniciación en la liturgia y en la oración personal; la "lectura" de la existencia humana a la luz de la fe, la educación para el ecumenismo, el compromiso con el mundo y otras más (21-30). Luego, con realismo por cuanto muchos resultan miembros de la Iglesia sólo por haber recibido determinados sacramentos, pero no manifiestan una efectiva y convencida adhesión personal a la fe, se proclama francamente que la catequesis, con frecuencia, debe, en realidad, hacerse cargo del anuncio kerigmático o, en otras palabras, asumir una "función evangelizadora" (18-19), como ya lo había afirmado Medellín².

- Criterios para el anuncio de los contenidos (36-46). Por primera vez, un documento catequístico del Magisterio universal reflexiona explícitamente sobre contenidos de la catequesis no solamente como referencia a los elementos constitutivos de la Revelación (fides quae), sino también en relación a la respuesta de fe del hombre (fides qua) (36). Así pues, se

30 Proemio del DCG.

31 Hacemos referencia a Groppo, "Direttorio Catechistico Generale”, 222.

32 La afirmación tendrá una larga prolongación en la reflexión catequética y en las declaraciones magistrales de los años siguientes. 
afirma que la comunicación del mensaje cristiano debe necesariamente referirse a las varias formas de vida socio-cultural y eclesial de los referentes, como también a sus múltiples lenguajes (37). En esa misma perspectiva, se propone la integridad del contenido como meta de la comunicación catequística (38) ${ }^{33}$. Solamente después de haber acogido los criterios que se deducen de la realidad social, cultural y psicológica que condiciona la fides qua del hombre, el DCG enumera otros criterios, que se derivan de la naturaleza de mensaje cristiano o fides quae. Estos vienen a ser: el respeto del mensaje como un todo orgánico y vital (39), el cristocentrismo (40), el teocentrismo trinitario (41), la atención a la finalidad "económica" del misterio cristiano (42), el respeto de la jerarquía de las verdades (43), de la dimensión histórica de la Revelación (44) y de la pluralidad de las fuentes (45).

- La exigencia antropológica o experiencial. Escrito entre finales de los años sesenta y el inicio de los años setenta, el DCG hace suya la renovación catequística en clave antropológica y experiencial entonces de actualidad. Así, también para el Directorio la catequesis "es el camino específico para descubrir en la propia vida el proyecto de Dios, para buscar el significado último de la existencia y de la historia" (21). Y sobre

33 La historia del movimiento catequístico se ha visto en muchos tramos marcada por la impronta fáctica mantenida por los innovadores para hacer aceptar en la Iglesia este principio que deriva necesariamente de las leyes psicológicas más elementales del aprendizaje humano. A modo de ejemplo, bastará citar la lección de la "gran señora" de la catequesis francesa, Marie Fargues (1884-1973) que, a partir del pensamiento de Montessori, enseña a regular la comunicación del mensaje cristiano respetando los diversos "periodos sensibles" que marcan la edad evolutiva, condenando la inutilidad de toda catequesis, por más abundante que sea en términos cuantitativos. En el mismo orden de idea, ella invita a seguir una "progresión no lógica, ordenada según el carácter de la doctrina, sino psicológica, ordenada según los intereses sucesivos del niño", teniendo en cuenta que "lo esencial para el niño no es un objetivo esencial" sino marcado por la subjetividad; y por consiguiente la integridad de la "doctrina" no puede ser más que una meta alcanzable sólo con la maduración de la persona. Comparte plenamente estos postulados basilares otro protagonista de la catequesis de más allá de los Alpes, Joseph Colomb (1902-1979) que, significativamente, titula su mayor propuesta catequística Catecismo progresivo, obra que fue causa inmediata la homónima crisis que en 1957 involucró a la catequesis francesa. Los supuestos enunciados son oficialmente acogidos por primera vez en un documento magisterial tan sólo en 1964, y precisamente en el directorio catequístico de los obispos de Francia. Para obtener mayores informaciones, Cf. G. Biancardi - U. Gianetto, Storia della catechesi 4, LAS, Roma 2016 (Storia 4) respectivamente en las 256-262 (la cit. de Fargues en las 260-261); 311-333 (sobre el pensamiento de Colomb, Cf. también el caprecedente); 337-339. 
el plano metodológico "es posible partir del hombre para llegar a Dios" (46), a través de una catequesis que se preocupa por evidenciar la dimensión soteriológica del mensaje cristiano (42) y acompaña a la persona hacia una asimilación progresiva del mismo mensaje (38) respetando la realidad humana $(34,37)$.

- La dimensión educativa del hecho catequístico. El cual involucra a personas que responden de modo único e irrepetible al don de la fe, con ritmos y tiempos absolutamente personales que deben ser atendidos individualmente con verdadera pasión educativa (30).

No obstante, el documento busca también huellas bastante evidentes de las preocupaciones presentes en la Iglesia, en el momento en que se estaba preparando. Las aprensiones del inmediato periodo posconciliar sobre posibles crisis, errores, tergiversaciones, actitudes heterodoxas en el campo de la fe, como se encuentran expresiones en los trabajos del primer Sínodo, hasta tal punto influyen en la redacción del Directorio que, particularmente en las últimas redacciones, es confiado prevalentemente a teólogos y no a catequetas ${ }^{34}$.

La mano de los teólogos resulta particularmente evidente - como se ha dicho - en el Addendum. A la luz de las preocupaciones ya citadas se comprenden mejor también los nn. 47-69 del DCG. Tales párrafos señalan, con toda evidencia, el listado de los criterios que deben guiar el anuncio del contenido catequístico (37-46) para una presentación, aunque sea esencial, de elementos doctrinales específicos a ser transmitidos. En efecto, ahí encontramos recogidos, en sus líneas más generales, los temas trinitarios, cristológicos, sacramentales, morales y eclesiológicos constitutivos de todo proceso catequístico que quiera ser completo y sistemático. Naturalmente, el documento no puede y no quiere decir más. Su objetivo no es formular una pequeña summa del mensaje cristiano. Así pues, el DCG, para retomar el lenguaje que ya hemos encontrado en los trabajos preparatorios del Concilio, no puede ser definido como un elencus, un enchiridion, o un syllabus de las verdades de fe; mucho menos puede ser visto propiamente como el Catechismus fons hipotizado siempre en la época conciliar. Pero, no obstante, el rapidísimo elenco de los contenidos presentados en los nn. 47-69 revela indudablemente que la preocupación por la integridad y la ortodoxia de la comunicación catequística anima la pluma 34 Groppo, "Direttorio Catechistico Generale", 221-222. 
de los redactores del Directorio y de las jerarquías romanas ${ }^{35}$. Y este dato evidencia una contradicción fácilmente reconocible en muchas catequesis postconciliares y en las declaraciones magistrales que la animan, incluido el DCG. Se la quiere renovada en sus finalidades, hasta el punto que son expresadas incluso con términos "nuevos", tales como madurez de la fe (21) o formación y similares, deducidos de las ciencias psicopedagógicas. Pero con frecuencia se piensa alcanzar las susodichas metas concentrándose, de hecho, sobre la comunicación de la fe guiada siempre por la tradicional configuración magisterial en función cognoscitiva; sin dar vida, en cambio, como sería necesario, a más articulados y complejos itinerarios capaces de procurar la efectiva receptio de la fe. Por lo cual, la renovación del ministerio catequístico propuesto se limita, la mayoría de las veces, a la búsqueda de nuevos métodos de comunicar la fe y alcanza a tocar los dinamismos más profundos de la personalidad que deberían conducir al catequizado a una efectiva acogida viva de la propuesta cristiana ${ }^{36}$.

Igualmente, emblemática de la cautela de la jerarquía en cuanto a catequesis resulta la norma reiterada varias veces, explícitamente (117, $119,134)$ o implícitamente $(106,118$ e 121), que somete a la aprobación de Roma - en concreto a la Congregación para el Clero - toda producción catequística de relieve de las conferencias episcopales (sobre todo directorios y catecismos, generalmente válidos a nivel nacional). La formulación más clara de la regla está en el n. 134 donde se establece que la susodicha congregación: Recognoscit ${ }^{37}$ et approbat directoria de catechesi, catechismos atque programmata praedicationis Verbi Dei a Conferentiis Episcoporum confecta38. El dispositivo, per se, retoma casi al

35 Simon, Un catéchisme universel, 308-310; Storia 4, 761-791.

36 Meddi, L'itinerario della fede oltre il catechismo, en su La catechesi oltre il catechismo. Saggi di catechetica fondamentale, Urbaniana University Press, Città del Vaticano 2017, 151-169 (ya en Catechesi 81 [2011-2012] 5, 3-18). Retomaremos el discurso, con ulterior bibliografia, a propósito del Documento base de la catequesis italiana.

37 "Recognoscit" remite a la tarea de la recognitio. Queda por especificar competentemente el exacto significado jurídico del término que ha usado sólo en años recientes el Consejo Pontificio para los textos legislativos con una Nota específica. Se puede encontrar Communicationes 38 (2006) 10-17, Notitiae 43 (2006) 376-384, Il Regno-Documenti 52 (2007) 23-26.

38 Los documentos sucesivos no hablarán más de recognitio y especificarán mejor que la approbatio no es necesaria para los textos catequísticos de cada ordinario en particular. 
pie de la letra el estilo de la constitución apostólica Regimini Ecclesiae universae del 1967, allí donde la misma establece que la Oficina Segunda de dicha institución: Recognoscit et approbat directoria de catechesi necnon programmata et schemata praedicationis Verbi Dei, in Conferentiis Episcoporum confecta (69 \$2). Sin embargo, la normativa va en otra dirección con respecto a las orientaciones precedentes: "Los documentos conciliares, Lumen Gentium y Christus Dominus [8-10 e 12-14] en particular, y el esquema del directorio de 1969 no dejaban en efecto presagiar un control romano sobre las actuaciones catequísticas de las conferencias episcopales" ${ }^{39}$.

Y la misma normativa, luego, aparece tanto más significativa si se considera que - al parecer - fue introducida autoritariamente en las fases finales de la elaboración de DCG, una vez concluidas las consultas de los episcopados locales ${ }^{40}$. El hecho parece fácilmente comprensible si se tiene en cuenta precisamente la situación eclesial del momento.

Han transcurrido cinco años [...] desde el final del concilio. El Directorio no puede no haber dejado de estar marcado por la cuestión del Ca-

39 Simon, Un catéchisme universel, 313.

40 Hablan de este procedimiento insólito también G. Duperray, "Une nouvelle crise de la catéchèse (1971-1983)”, Lumen Vitae 33 (1984) 169, 5-23; y 6-7, y R. Marlé, "Un catéchisme de l'Église catholique", Études 136 (1992) 377, 689-695; y 690. La voz de diversos catequistas se alzó muy crítica con relación a esta normativa. Vayan como muestra todas estas expresiones: "Parece ser la primera vez en la historia de la Iglesia que Roma se atribuye un papel de verificación de los actos episcopales en materia de enseñanza ordinaria de la fe. No están tan lejanos los tiempos en los que cada obispo consideraba un derecho propio irrenunciable el ser dueño de su "propio" catecismo. No es posible que la colegialidad nacional, que guía actualmente la elaboración de los instrumentos de la catequesis y les da necesariamente un valor y autoridad mucho más fuerte, acabe en un centralismo que no ha sido querido por el Vaticano II", G. Duperray, "Le ministère de la parole comme action pastorale", Supplément a Catechèse 11/45 (1971) 195-218; y 214. La misma línea de pensamiento sigue Adler: "Difícilmente nos imaginamos al episcopado postridentino dejarse despojar tan fácilmente del propio derecho, y mucho menos a Cipriano, Agustín, Dupanloup, Landrieux...". G. Adler, "La catéchèse: où est le probleme? ”, Études 127/358 (1983) 829-843; y 841. Para una reflexión más general sobre las intervenciones de Roma en ámbito catequístico, ver: E. Alberich, "La catéchèse entre centralisation et pluralisme. Le rôle de Rome dans le fonctionnement de la pratique catéchétique", Enseigner, 379-388. 
tecismo Holandés y por la "crisis de fe" que inquieta a los ambientes romanos. Entre el esquema inicial del cual las conferencias episcopales tuvieron conocimiento en 1969 y el texto definitivo del 11 de abril de 1971, son perceptibles algunas diferencias que manifiestan una cierta insistencia sobre la integridad de la fe y la interpretación correcta de la enseñanza de la Iglesia.

\section{El Directorio General para la Catequesis (DGC, 1997)}

El Congreso Catequístico de 1997 fue la ocasión, también, para la presentación oficial de un nuevo Directorio catequístico que, con el título oficial de Directorio General para la Catequesis, vino a sustituir el de 1971, mostrando múltiples referencias al CCC. ${ }^{41}$

\subsection{Orígenes y redacción del DGC ${ }^{42}$}

41 Texto en: Congregatio pro Clericis, Directorium generale pro catechesi, Città del Vaticano, Lib. Ed. Vaticana 1997; EV 16, 608-1011 (testo lat. e it.); Congregazione per il Clero, Direttorio Generale per la Catechesi, Città del Vaticano, Lib. Ed. Vaticana 1997.

42 De la amplísima bibliografía sobre el Directorio en el momento de su salida destacamos, Cf. G. Adler, "Directoire général pour la catéchèse. Exercice de lecture", in Catechèse 38/152 (1998) 90-96; E. Alberich, "Un documento eclesial para dar un nuevo impulso a la catequesis evangelizadora", Misión Joven 38/255 (1998) 13-18; C. Bissoli, "Il Direttorio Generale per la Catechesi. Origine, contenuti, confronto", Salesianum 60 (1998) 521-547; C. Bissoli, "Di fronte al "Direttorio generale per la catechesi". Provocazioni e orientamenti per la catechesi italiana", Catechesi 68/4 (1998) 19-31; "Congregación para el Clero. Directorio General para la Catequesis. 15 de agosto de 1997”, Catecheticum 1 (1998) 157-164; H. Derroitte, "Les tâches de la catéchèse. Regards sur le Directoire Général pour la Catéchèse", Lumen Vitae 53 (1998) 103-112; en las 91-102, también A Fossion, Un nouveau Directoire Général pour la Catéchèse; J.M. Estepa Llaurens, "Presentación del Directorio General para la Catequesis", Actualidad Catequética 38 (1998) 97109; U. Gianetto, "El nuevo Directorio General para la Catequesis", Misión Joven 38/255 (1998) 5-11; las páginas monográficas de The Living Light 34/2 (1997-1998) 8-63; y de Catechesi Missionaria 14 (1998) 1, 3-58; L. Alves de Lima, "Introdução ao Novo Diretório Geral para a Catequese”, Revista Eclesiástica Brasileira 59 (1999) 281-312; J. López Martín, "Il Directorio General para la Catequesis y la liturgia", Phase 38 (1998) 191-202; R. Paganelli, "Il nuovo Direttorio per la catechesi", Settimana 31/41 (1997) 8-9; T. Stenico, "El Espíritu Santo "que es Señor y da la vida" y la misión evangelizadora de la Iglesia. Lectura a la luz del Catecismo de la Iglesia Católica y del Directorio General para la Catequesis", Actualidad Catequética 38 (1998) 27-52; Sociedad de Catequetas Latinoamericanos (SCALA), Encrucijadas de la catequesis a la luz del Directorio General para la Catequesis [...], 
El DGC quiso ser una revisión del $\mathrm{DCG}^{43}$. La revisión quedaba justificada por la exigencia de integrar en un nuevo documento toda la problemática catequística desarrollada en los últimos 25 - 30 años, a partir del DCG. En particular, se sentía la necesidad de repensar y reformular orgánicamente las aportaciones de documentos como Evangelii Nuntiandi (EN 1975), Catechesi Tradendae (CT 1979) y encíclicas como la Redemptoris Missio (1990). Sobre todo, se trata de tener en cuenta la publicación del Catecismo de la Iglesia católica (CCC). Nadie pretende negar la validez del DCG o disminuir la importancia en la historia de la catequesis posconciliar; importancia, por lo demás, reconocida también por CT 2 y 50. Pero se toma nota de que la reflexión catequística ha tenido, después del DCG, una notable evolución. EN, por ejemplo, dilató grandemente el significado de la evangelización. CT, por su parte, profundizó la especificidad de la catequesis en relación al conocimiento sistemático y exacto de la fe, mientras el CCC se ha situado como respuesta precisa a esta tarea del ministerio catequístico. A partir del DCG, además, la reflexión teológico-pastoral profundizó sobre temas decisivos del campo catequístico como la inculturación y la catequesis de los adultos. También las ciencias humanas, en particular las pedagógicas, desarrollaron su aportación en el campo de la pedagogía religiosa. De ahí, justamente, tras los años ochenta y noventa, el lento madurar de la hipótesis de una revisión del primer Directorio catequístico de la Iglesia ${ }^{44}$.

La exigencia se deja sentir desde 1992 dentro del COINCAT, con ocasión de su ya octava sesión dedicada al tema: Inculturación de la fe $y$ lenguajes de la catequesis ${ }^{45}$. El año siguiente, y precisamente el 30 de noviembre de 1993, el cardenal Sánchez, como prefecto de la Congregación para el Clero, envía un cuestionario a los presidentes de las

San José (CR), Editorial CONEC 1999. Cf. también los números monográficos de Actualidad Catequética 37/176 (1997), Sinite 39/117 (1998); Teología y Catequesis 17/67 (1998); Teología y Catequesis 18/69 (1999); Medellín 24/96 (1998) 551-629. En el décimo y vigésimo aniversario de la promulgación aparecieron nuevos estudios sobre el documento que sería muy extenso citar.

43 Schulte, "The Influence of the 1971 General Catechetical Directory and Prospectives for the Revised Directory", The Living Light 34/2 (1997-1998) 41-44.

44 "La IX Sessione plenaria del Consiglio Internazionale per la Catechesi (COINCAT) (20-23 settembre 1994)", Sacrum Ministerium 1 (1995) 71-83, 72-76.

45 "La IX Sessione plenaria del Consiglio Internazionale" 72. 
comisiones episcopales de la catequesis, a los institutos de catequética ${ }^{46}$, a los miembros del COINCAT y a varios expertos, entre ellos a algunos redactores del DCG. Las siete preguntas versan precisamente sobre la oportunidad y modalidades de una eventual revisión del $\mathrm{DCG}^{47}$. Sobre la base de las 47 respuestas recibidas se toma nota de que la orientación emergente es en favor de una revisión de tipo moderado; ninguno pide un cambio radical, e incluso, cinco respuestas se muestran contrarias a ningún tipo de cambio.

Las aportaciones de la consulta permiten la elaboración de una especia de Instrumentum laboris que propone Observaciones y propuestas para la actualización y revisión del DCG. Se acepta la orientación y la revisión "moderada" sobre la base de tres motivaciones fundamentales, es decir la necesidad de integrar en un documento "revisado":

- La memoria catequística de la Iglesia a partir de 1971 (documentos sinodales y pontificios, documentos de la renovación litúrgica, congresos catequísticos...);

- La publicación del CCC;

- La exigencia sobre la nueva evangelización insistentemente reiterada por Juan Pablo II.

El texto de Observaciones y propuestas de junio de 1994 es enviado a los miembros del COINCAT y a los expertos asociados al mismo, para obtener indicaciones sobre todo con respecto a la revisión moderada del DCG ${ }^{48}$.

El organismo consultivo de la Congregación para el Clero tuvo su novena sesión plenaria entre el 20 y el 23 de septiembre de 1994. Concretamente, en esta oportunidad es cuando se pone en marcha el trabajo de revisión del DCG. Cada jornada de trabajo se ve orientada por un informe de fondo, inspirado en las diversas partes del DCG: el catequista español Mons. J.M. Estepa Llaurens, redactor tanto del DCG

46 Sobre la implicación real de los institutos de catequética en toda la preparación del DGC, Bissoli, Il Direttorio Generale per la Catechesi. Origine, contenuti, confronto, 527, nota 20, y 535-536, nota 33. Seguiremos con particular atención esta contribución porque su aportación desempeñó un papel de primer orden en la redacción del DGC.

47 Bissoli, Il Direttorio Generale per la Catechesi. Origine, contenuti, confronto, 527.

48 Cf. La IX Sessione plenaria del Consiglio Internazionale per la Catechesi, 76. 
como del CCC, examina la primera y sexta parte del directorio a ser revisado, que trata de La pastoral del ministerio de la Palabra, el P. B. Duroux, OP., ya colaborador en la redacción del DCG, repasa la segunda y tercera parte de dicho documento, ilustrando El mensaje cristiano, finalmente D. Bissoli, DDB, catedrático de disciplinas catequísticas en la Universidad Pontificia Salesiana, retoma la cuarta y quinta parte del DCG, reflexionando sobre los Elementos de metodología catequística ${ }^{49}$.

El informe y los debates que le siguen ponen de relieve algunos puntos cruciales a ser resueltos, tales como la relación entre CCC y DCG, a los cuales hace referencia el mismo catecismo universal; la identidad de la catequesis y del catequista; la relación entre catequesis y enseñanza de la religión; el problema de la jerarquía de las verdades y de la comunicación ${ }^{50}$.

Recogiendo las aportaciones de la discusión, un equipo reducido ${ }^{51}$ propone a la asamblea un esquema de trabajo provisional y algunos criterios de redacción del nuevo texto inspirado en el DCG que quedan formulados de la siguiente manera:

- El dictamen sobre el trabajo realizado resulta sustancialmente positivo;

- Atiende a la continuidad con el DCG, pero también a la valoración del enriquecimiento catequístico sucesivo;

- Referencia a los acontecimientos eclesiales-catequísticos que han tenido lugar después de 1971;

- Libertad en la ubicación de los contenidos, para una nueva y más clara síntesis;

- Cita literal de los textos del magisterio;

- Valoración de la estructura "cuatripartita" del CCC;

- Mantenimiento de la estructura "fluida" del DCG;

49 La IX Sessione plenaria del Consiglio Internazionale per la Catechesi, 76-78.

50 Para profundizar más sobre las cuestiones debatidas, en Bissoli, Il Direttorio Generale per la Catechesi. Origine, contenuti, confronto, 528-530.

51 Formaban parte de él Mons. J.M. Estepa Llaurens, Mons. J. Medina Estevez, el B. Duroux, C. Bissoli, G. Groppo. Bissoli, Il Direttorio Generale per la Catechesi. Origine, contenuti, confronto, 530. 
- Atención a la inculturación, solicitada por el COINCAT así como también por el Papa, mediante una carta del 21 de septiembre de1993. ${ }^{52}$

El trabajo concreto de redacción fue confiado, el 29 de noviembre de 1994, a Mons. J.M. Estepa Llaurens para la introducción, I, II, V parte; a C. Bissoli para las partes II y IV. Los redactores trabajaron individualmente durante todo el 1995, con algunas sesiones de puesta en común. En febrero de 1996 la primera redacción es sometida a la consulta de la conferencia episcopal y a algunos centros de estudio. El documento va acompañado por una serie de anotaciones preliminares, un glosario básico, un cuestionario o tabla de valoración. 168 personas o instituciones resultan consultadas. Las respuestas suman 93 (cifra considerada elevada). Según el testimonio de Bissoli:

- El juicio sobre el trabajo realizado resulta sustancialmente positivo;

- Las Iglesias pobres en recursos, tales como las jóvenes Iglesias y las del Este europeo, aprecian la amplitud del documento, considerándolo casi como un manual inmediatamente utilizable, mientras que las iglesias occidentales solicitan una mayor sobriedad, en sintonía con DCG;

- El problema de la inculturación es apreciado en países como los de América Latina mientras que casi no es tomado en consideración en el área anglófona;

- Se ponen en evidencia, como límites de contenido: la no homogeneidad de las partes, el lenguaje a veces genérico y abstracto, la carencia de precisiones de conceptos clave como revelación, evangelización, catequesis, catecumenado, inculturación, relaciones entre catequesis y otras formas de la praxis pastoral ${ }^{53}$.

Tras la compleja catalogación de todas las observaciones recibidas, los dos redactores proceden a una nueva elaboración del documento, entregada a la Congregación para el Clero en enero de 1997 para

52 Bissoli, Il Direttorio Generale per la Catechesi. Origine, contenuti, confronto, 530-533. La carta de Juan Pablo II que insiste sobre la inculturación está expuesta en La IX Sessione plenaria del Consiglio Internazionale per la Catechesi, 78-80. Algunas dudas sobre la efectividad y la correcta valoración del principio de inculturación en el texto concreto del DGC se encuentran expresada por L. Meddi, "La inculturazione della fede nella nuova "catechesi missionaria". Le ambiguità del Direttorio generale per la catechesi (1997)”, en S. Mazzolini (ed.), Vangeli e culture. Per nuovi incontri, Città del Vaticano, Rubaniana University Press 2017, 147-167.

53 Bissoli, Il Direttorio Generale per la Catechesi. Origine, contenuti, confronto, 534-538. 
una tercera y definitiva redacción, que implica a la misma Congregación y la de la Doctrina de la $\mathrm{Fe}^{54}$. Es el texto aprobado por el Papa y hecho público en la solemnidad de la Asunción de 1997, con la firma de Mons. D. Castrillón Hoyos, pro-prefecto de la Congregación para el Clero, y del secretario de la misma Mons. C. Sepe.

El documento es enviado a la imprenta en el siguiente mes de septiembre ${ }^{55}$ y luego presentado oficialmente a la Iglesia durante la celebración del Congreso Catequístico de octubre. De hecho, este acto constituye la segunda finalidad confiada a la tercera sesión catequística internacional.

Para presentar el nuevo DGC a los congresistas realiza una exposición el pro-prefecto Mons. Castrillón Hoyos, con el fin de ilustrar los motivos y los criterios de la revisión del antiguo Directorio $0^{56}$. Sus afirmaciones vienen completadas con la ya aludida exposición del cardenal Ratzinger sobre el CCC y con, por lo menos, otras dos presentaciones fundamentales desarrolladas durante el Congreso. Nos referimos sobre todo a la intervención de Mons. Estepa Llaurens que expone el tema: La misión profética de la Iglesia: evangelización, catequesis y CCC ${ }^{57}$. Como se deduce fácilmente del título, al catequeta español se le pide centrar la atención principalmente sobre el CCC, pero al ser uno de los principales redactores del DGC, las referencias a este nuevo docu-

54 Véase la afirmación de Bissoli según la cual existe "fidelidad sustancial" entre la segunda y la tercera redacción. La intervención de los dos dicasterios romanos sobre el texto preparado por Mons. Estepa y Bissoli habría sido sobre todo de tipo formal, con algunas precisiones a nivel de contenidos, especialmente en el tema de las relaciones entre DGC y CCC.

55 La conferencia de prensa es del 18.9.1997. Las dos exposiciones leídas en aquella ocasión fueron: D. Castrillón Hoyos, Lettura teologico-pastorale y C. Sepe, "Motivazioni, origini e caratteristiche”, L'Osservatore Romano del 19.9.1997, 1 e 4. Los dos textos también en Actualidad Catequética 7 (1997) 563-577.

56 Cf. L'Osservatore Romano del 16.10.1997, 16-17; la presentación se halla también en: T. Stenico (ed.), Evangelizzazione, catechesi, catechisti, 40-67, Actualidad Catequética 37 (1997) 591-615 y en Rivista de Catequese 21 (1998) 81, 5-21. A la presentación de Mons. Castrillón Hoyos le siguen seis comunicaciones de representantes de los diversos continentes que retoman el papel desempeñado por el DCG en las diversas áreas eclesiales. Una breve referencia a dichas presentaciones se halla en Bissoli, Il Direttorio Generale per la Catechesi. Origine, contenuti, confronto, 523524 , nota 11 , y 539, nota 40.

57 La presentación se ofrece integralmente en Actualidad Catequética 37 (1997) 617-639. 
mento son continuas. Aún más evidente es la disertación del obispo filipino Mons. L. Z. Legaspi, OP, que aborda explícitamente el argumento: El CCC y el DGC como puntos de referencia para la redacción de los directorios catequísticos $y$ de los catecismos nacionales. ${ }^{58}$

En conjunto, todas estas presentaciones ofrecen una útil clave de lectura del nuevo Directorio.

\subsection{Contenidos}

El DGC se abre con una amplia Introducción que esboza la tarea del anuncio evangélico por parte de la Iglesia en el mundo actual (n. 14-33).

La Parte I, identifica en este amplio campo de acción la ubicación y la contribución específica de la catequesis (34-91: La catequesis en la misión evangelizadora de la Iglesia). El objetivo se logra mediante tres pasajes sucesivos que acotan cada vez más el terreno de la reflexión: en efecto, se pasa de una reflexión más general sobre la Revelación y sobre su transmisión a través la evangelización (cap. $1^{\circ}$ ), a una precisión posterior sobre la catequesis en el proceso mismo de la evangelización (cap. $2^{\circ}$ ) y finalmente, a individualizar, la naturaleza, finalidades y tareas del ministerio catequístico específico (cap. $\left.3^{\circ}\right) .59$

En la Parte II, el documento se cuestiona sobre el contenido del anuncio catequístico (92-36: El mensaje evangélico). Primeramente, el Directorio enumera las normas y los criterios para la presentación del mensaje evangélico en la catequesis (cap. $1^{\circ}$ ) para pasar luego a una reflexión sobre el contenido a ser transmitido a la luz del CCC, punto de referencia para todo catecismo local (cap. $\left.2^{\circ}\right)^{60}$.

58 Texto íntegro Actualidad Catequética 37 (1997) 641-653. A continuación, en las 655-688, es posible encontrar las otras dos presentaciones fundamentales del congreso: la de Mons. J. Olorufemi Onaiyekan, obispo nigeriano, sobre La pedagogia della fede e l'adattamento della catechesi ai destinatari, y la de Mons. M. El-Hacem, obispo en Líbano, que ilustra La formazione degli operatori pastorali della catechesi e l'organizzazione pastorale e catechistica nelle Chiese particolari. Bissoli, Il Direttorio Generale per la Catechesi. Origine, contenuti, confronto, 539, nota 40.

59 V.M. Pedrosa, "El concepto de catequesis en el nuevo Directorio general para la Catequesis”, Teología y Catequesis 18/69 (1999) 41-63.

60 R. Lázaro Recalde, "El mensaje evangélico en la catequesis. Un comentario a 
Con la Parte III, el DGC orienta sobre la atención a la pedagogía y metodología de la comunicación catequística (137-162: La pedagogía de la fe). Como es natural, la reflexión se inicia a partir de la pedagogía de Dios, fuente y modelo de toda intervención pedagógica al servicio de la fe $\left(\right.$ cap. $\left.^{\circ}\right)$, para pasar luego a especificar algunos elementos fundamentales de metodología catequística $\left(\text { cap. } 2^{\circ}\right)^{61}$.

La atención a las referencias de la catequesis, ya presentadas en los párrafos precedentes, se vuelve aún más explícita y puntual en la Parte IV dedicada a: Los destinatarios de la catequesis (163-214). Como punto de partida se plantea un análisis sobre los aspectos generales de la adaptación al destinatario del anuncio catequística (cap. $1^{\circ}$ ), pero a continuación el discurso se caracteriza por referencias puntuales a las concretas situaciones en las que se encuentra viviendo el sujeto-destinatario del mensaje. El DGC trata, así, sucesivamente, sobre la catequesis según las diversas edades (cap. $2^{\circ}$ ), para situaciones especiales, mentalidades y ambientes diversos (cap. $3^{\circ}$ ), en los varios contextos socio-religiosos (cap. $4^{\circ}$ ) y socio-culturales (cap. $5^{\circ}$ )..$^{62}$

La Parte quinta, la última desarrolla el tema de los agentes de la catequesis, poniendo el énfasis sobre cómo la Iglesia particular debe ser la primera responsable (215-285: La catequesis en la Iglesia particular). En la comunidad creyentes, existen agentes concretos dedicados al servicio de la catequesis (cap. $1^{\circ}$ ), que deben ser adecuadamente formados (cap. $2^{\circ}$ ). Pero la Iglesia particular no puede confiar solamente a algunos la catequesis. En cambio, la misma está llamada a valorar los múltiples lugares y las innumerables vías a través de las cuales el mensaje evangélico puede llegar al hombre (cap. $3^{\circ}$ ). Podrá desempeñar este deber cuidando oportunamente la organización de la propia pastoral catequística $\left(\right.$ cap. $\left.4^{\circ}\right) .{ }^{63}$

DGC 94-118”, Teología y Catequesis 18/69 (1999) 65-88.

61 J.C. Carvajal Blanco, "La pedagogía de la fe, servidora de la Revelación", Teología y Catequesis 26/104 (2007) 59-90.

62 Cf. L. Otero Outes, "Catequesis, pedagogía de la fe y destinatarios de la catequesis en el nuevo Directorio general para la Catequesis", Teología y catequesis 18/69 (1999) 89-114; M.Á. Gil, "Los destinatarios de la catequesis", Teología y catequesis 26/104 (2007) 91-111.

63 Se reafirma, en este cap., la normativa del Código, integrada por la de la Constitución 
Una Conclusión de tono augural y que invita a invocar en la oración la ayuda de Dios y de la Virgen María clausura el documento $(286-291)$.

\subsection{Valoración}

\subsubsection{Elementos de continuidad con el Directorio precedente}

Queriendo intentar expresar un juicio necesariamente breve sobre un documento tan complejo, podemos, antes que nada, evidenciar los elementos de continuidad que lo vinculan con el DCG. Las relaciones entre los dos textos magistrales aparecen no sólo en las más de 70 referencias explícitas del Directorio al DCG, sino en diversos otros puntos. Resultan comunes, por ejemplo:

- La inspiración conciliar;

- La asignación del papel absolutamente primordial atribuido a la Escritura en el proceso catequístico;

- La atenta referencia al Magisterio y a las otras grandes asambleas de la Iglesia (Concilios y Sínodos);

- La diversa importancia atribuida - naturalmente - a los temas fundamentales en el campo catequístico (como la Revelación, la naturaleza de la catequesis, los criterios del anuncio) y aquellos otros de tipo más "aplicativo" (como el método y las formas de la catequesis);

- El subrayado de la importancia atribuida a la comunidad, al grupo, a la experiencia humana, a la formación de los catequistas, etc. ${ }^{64}$

\subsubsection{Elementos de novedad y de acentuaciones positivas}

Igualmente, evidentes, y quizás incluso más, los elementos de novedad y las acentuaciones más significativas que diferencian el nuevo del antiguo Directorio.

Apostólica Pastor Bonus, sobre l'approbatio de la Congregación del Clero para catecismos y directorios de las Conferencias episcopales. Cf. los nn. 271, 282 e 285. Un comentario en C. Aguilar Grande, "La catequesis en la Iglesia particular", Teología y catequesis 26/104 (2007) 113-135.

64 Bissoli, Il Direttorio Generale per la Catechesi. Origine, contenuti, confronto, 540-541; Fossion, Un nouveau Directoire Général pour la Catéchèse, 94. 
El DGC se presenta materialmente como un texto mucho más amplio que el precedente: más de 300 páginas contra un centenar del texto precedente, y 291 parágrafos contra 134 del DCG, lo cual indica que el criterio de atenerse a la "estilización" del antiguo Directorio ha quedado indudablemente olvidado. Además, al nuevo documento se le ha suprimido el addendum, por considerarlo no pertinente en un directorio de tipo general.

Pero, más allá de los aspectos exteriores, es posible subrayar en el DGC los siguientes aspectos peculiares:

- La ubicación de la catequesis en el dinamismo de la evangelización, en línea con EN. La catequesis resulta ubicada dentro de una óptica resueltamente misionera. Por eso se habla de catequesis en estrecha relación con el primer anuncio (orientada a la conversión), luego de la catequesis de la iniciación (muy vinculada con los sacramentos de la iniciación) y permanente (de los creyentes y de las comunidades que profundizan la fe). Los tres tipos de catequesis son considerados como necesarios y complementarios $(60-72){ }^{65}$

- La valoración del catecumenado bautismal como modelo inspirador de la catequesis, como consecuencia lógica de la visión actualmente exigida por los catequistas (88-91). ${ }^{66}$

- La concepción de catequesis como formación integral, según la cual es ciertamente instrucción, pero también iniciación a la vida cristiana en sus diversos aspectos (84-87). ${ }^{67}$

- La atención a la fidelidad conjuntamente a Dios y al hombre. La reafirmada fidelidad a Dios lleva, entre otras cosas, a la reposición del concepto conciliar de Revelación $(36,39,131)$, mientras que la llamada a la fidelidad al hombre conduce a reafirmar la importancia de la atención a la experiencia humana (n. 152 del DGC que retoma el n. 74 del D71; además del n. 153), a la inculturación (109-110,203-207) y a una catequesis progresiva que preste atención a las situaciones y a las exigencias del destinatario del mensaje. ${ }^{68}$

65 Fossion, Un nouveau Directoire Général pour la Catéchèse, 94. Una tal perspectiva en el modo de considerar la catequesis debería resultar en adelante clara, con solo pensar en cuanto se ha dicho en las páginas precedentes sobre temas como "catequesis evangelizadora" y gracias a la irrupción de la idea de "evangelización” en el léxico eclesiástico de los años setenta.

66 Fossion, Un nouveau Directoire Général pour la Catéchèse, 95.

67 Fossion, Un nouveau Directoire Général pour la Catéchèse, 95

68 Se advierte el subrayado de Adler, Directoire général pour la catéchèse, 92: el con- 
- La revalorización de la Tradición. El DGC insiste para que, en la catequesis, además de poner en contacto al catequizando con la Biblia, se valore el dato de la Tradición (42-45). ${ }^{69}$ Dentro de esta perspectiva, comprendemos cómo dentro del nuevo Directorio se pueda encontrar un renovado aprecio del género "catecismo", considerado justamente como texto que recoge en síntesis las aportaciones de la Tradición.

\subsubsection{El DGC y el CCC}

Esta última mención nos lleva espontáneamente a detenernos por un momento sobre la insistente atención reservada al DGC y al CCC ${ }^{70}$, ciertamente uno de los elementos innovadores de mayor relieve en el nuevo Directorio. Nos interesa de modo particular captar en qué sentido el DGC interpreta la problemática calificada como "punto de referencia" para los catecismos locales atribuida al catecismo universal.

El DGC dedica - como ya hemos señalado - amplio espacio al CCC: de hecho, un capítulo entero. La innovación, respecto al DCG, es evidente mientras que este primer Directorio se contentaba con determinar algunos criterios fundamentales para el anuncio cristiano, el nuevo documento enumera también una amplia criteriología (94-118), pero poco después, en el capítulo "Esta es nuestra fe, esta es la fe de la Iglesia” (119-136), continúa reflexionando sobre los contenidos catequísticos. El discurso se centra entonces sobre CCC (considerado precisamente como conjunto ejemplar de los contenidos de la fe), y sobre las relaciones de este texto universal con la catequesis local.

Señalemos, al respecto, que casi la mitad del capítulo sobre CCC está reservada precisamente a ilustrar identidad y funciones de los catecismos locales, además de sus relaciones con los recursos de la Iglesia (131-136). Las indicaciones del nuevo Directorio reafirman la necesidad de verdaderos catecismos particulares "adaptados e inculturados" (131 y 153) aclarando lo que significa inculturar con creatividad el mensaje cristiano a nivel diocesano, regional y nacional (132-135). Coherentemente con

cepto de "progresividad", condenado en Colomb, se ve oficializado varias veces en el DGC, al menos en los nn. 88, 112, 129 nota 28.

69 Fossion, Un nouveau Directoire Général pour la Catéchèse, 95-96.

70 B. Sklodowski, "Le Catéchisme de l'Église catholique entre deux directoires catéchétiques”, LV 69 (2014) 381-397. 
estos enunciados se deja a los textos locales la libertad de estructurar los contenidos "con diversas articulaciones y configuraciones". Todo ello porque "el Catecismo de la Iglesia Católica ha sido propuesto como referencia doctrinal, pero no se desea con ello imponer a toda la Iglesia una configuración determinada de catecismo". Y se reconoce, en consecuencia, que existen legítimamente catecismos "con una configuración trinitaria, otros [...] estructurados según las etapas de la salvación, otros según un tema bíblico y teológico de gran densidad (Alianza, Reino de Dios, etc. ...), otros según la dimensión de la fe, otros según el año litúrgico" (135). Dada esta libertad, CCC y los textos catequísticos locales juntos tienen una función importante: expresar la unidad y la armonía de la única fe, la catolicidad de la Iglesia, la comunión eclesial y la colegialidad de los obispos (136).

Todo ello debería ahuyentar los temores de cuanto había supuesto, a veces no sin razón, una limitación de la imprescindible tarea eclesial en favor de la inculturación de la fe. ${ }^{71}$

Pero, es indudable que el tema del CCC está muy enfatizado en el nuevo Directorio, tanto que - según Fossion - se tiene a veces la impresión de que el documento tiende a identificar sic et simpliciter el CCC con la Tradición (128). Además, en el n. 125, el subsidio universal es explícitamente presentado como "fuente" de la catequesis, aunque no única y no superior a la Palabra de Dios (a la cual, por otra parte, el DGC dedica menor atención que al CCC). Ahora bien, calificar al Catecismo como "fuente" para el ministerio catequístico parece excesivo y causa de ambigüedad ${ }^{72}$. Además, el n. 120 concibe el Directorio como "instrumento metodológico" para la "aplicación concreta "del CCC, cuando, en todo caso, debería ser al contrario; en efecto, objetivamente, es el texto universal "el que constituye un instrumento al servicio del proceso y de la realización de la catequesis, proceso y realización ampliamente expuestos en el nuevo Directorio". ${ }^{73}$

71 Sobre este punto hemos retomado Biancardi, I primi cinque anni, 16-17. Un comentario sobre los enunciados del DGC sobre señalaciones es ofrecido por: J. Saraiva Martins, "Il CCC e l'inculturazione della fede", y L. Chiarinelli, "Il CCC punto di riferimento per i catechismi nazionali e regionali”, en T. Stenico (ed.), Evangelizzazione, catechesi, catechisti, Editrice Vaticana, Roma 1999, 299-335.

72 Fossion, Un nouveau Directoire Général pour la Catéchèse, 100-101.

73 Alberich, Il nuovo Direttorio Generale per la Catechesi, 1108. Cf. A. Cañizares, Il CCC 


\subsection{Observaciones críticas}

Estas últimas señalaciones nos conducen a concluir nuestra presentación del DGC con algunas observaciones críticas expresadas por los expertos en la materia. Catequistas y pastoralistas ponen de manifiesto en el documento:

- Una lectura actual de la sociedad que subraya sólo los elementos negativos en cuanto a apertura a la fe y a la religión en general: del mundo actual se ponen de manifiesto el secularismo, el ateísmo, la indiferencia y otros elementos negativos, sin poner de relieve los aspectos de apertura a lo trascendente; ${ }^{74}$

- Una concepción instrumental o "ancilar" de las ciencias humanas;

- Una ocultación, di fatto, del papel de la Palabra de Dios en el proceso catequístico; ciertamente se declara su importancia en orden a la catequesis, pero luego, en concreto, el documento no aborda ninguna reflexión sobre las funciones y sobre los diversos usos de la Palabra en la catequesis; el silencio se manifiesta tanto más claramente cuando se considera el amplio espacio dedicado en cambio a la reflexión sobre el uso y las funciones de los catecismos y del CCC en particular;

- Por último, la colocación tradicional de la Confirmación después de la Eucaristía, sin la debida atención al más correcto orden de sucesión indicado por la tradición antigua y por la reflexión teológica actualizada. ${ }^{75}$

chiave di interpretazione del Direttorio Generale per la catechesi, en Stenico (ed.), Evangelizzazione, catechesi, catechisti, 336-372.

74 Fossion, Un nouveau Directoire Général pour la Catéchèse, 98-99; el mismo nivel crítico se encuentra en Adler, Directoire général pour la catéchèse, 93-94.

75 Fossion, Un nouveau Directoire Général pour la Catéchèse, 99-101. Sobre este particular, con respecto al orden cronológico de los acontecimientos, antes de continuar debemos por lo menos señalar la celebración del Jubileo internacional de los catequistas (Roma, 9-10 diciembre 2000). Documentación al respecto en: Stenico, Giubileo dei catechisti 9-10 dicembre 2000. Il Catechista nella missione della Chiesa testimone di Cristo ieri oggi e sempre, Lib. Ed. Vaticana, Città del Vaticano 2000; Congregazione per il Clero, Catechisti della nuova evangelizzazione "Il Papa vi dice: Andate", a cargo de M. Piacenza, Genova, Marietti 2001, con CD adjunto; AC 40 (2000) 527-562 y Sacrum Ministerium 6/2 (2000) 5-35; 75-140: con homilías, intervenciones y crónicas del evento; J. Ratzinger, "La nouvelle Évangélisation", en Catechèse 41/163 (2000) 78-88 (conferencia que tuvo lugar con ocasión del Jubileo; reproducida también en otros texto citados). 